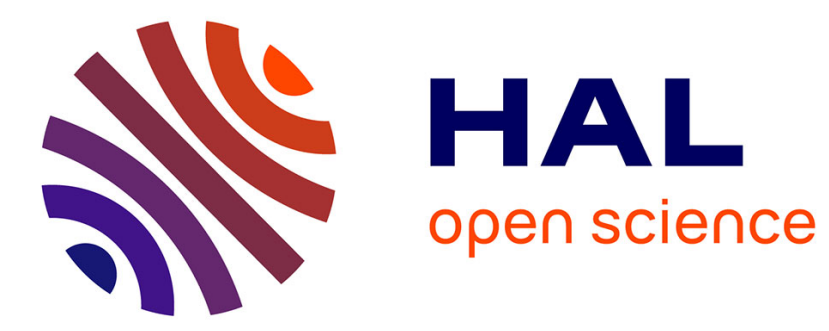

\title{
Coherent anti-Stokes Raman scattering study of the dynamics of a multipolar plasma generator
}

\author{
M. . Lefebvre, M. Péalat, J.-P. Taran, M. Bacal, P. Berlemont, D. Skinner, J.
} Bretagne, R. Hutcheon

\section{- To cite this version:}

M. . Lefebvre, M. Péalat, J.-P. Taran, M. Bacal, P. Berlemont, et al.. Coherent anti-Stokes Raman scattering study of the dynamics of a multipolar plasma generator. Journal de Physique II, 1992, 2 (3), pp.295-314. 10.1051/jp2:1992135 . jpa-00247633

\section{HAL Id: jpa-00247633 https://hal.science/jpa-00247633}

Submitted on 1 Jan 1992

HAL is a multi-disciplinary open access archive for the deposit and dissemination of scientific research documents, whether they are published or not. The documents may come from teaching and research institutions in France or abroad, or from public or private research centers.
L'archive ouverte pluridisciplinaire HAL, est destinée au dépôt et à la diffusion de documents scientifiques de niveau recherche, publiés ou non, émanant des établissements d'enseignement et de recherche français ou étrangers, des laboratoires publics ou privés. 
Classification

Physics Abstracts

33.20 F $-52.50 \mathrm{D}$

\title{
Coherent anti-Stokes Raman scattering study of the dynamics of a multipolar plasma generator
}

\author{
M. Lefebvre $\left({ }^{1}\right)$, M. Péalat $\left({ }^{1}\right)$, J.-P. Taran $\left({ }^{1}\right)$, M. Bacal $\left({ }^{2}\right)$, P. Berlemont $\left({ }^{2}\right)$, D.A.Skinner $\left({ }^{2}\right)$, \\ J. Bretagne $\left({ }^{3}\right)$ and R.J. IIutcheon $\left({ }^{4}\right)$
}

(1) Office National d'Etudes et de Recherches Aérospatiales, 29 Avenue de la Division Leclerc, 92320 Châtillon, France

$\left({ }^{2}\right)$ Laboratoire de Physique des Milieux Ionisés, Laboratoire du CNRS, Ecole Polytechnique, 91128 Palaiseau, France

$\left({ }^{3}\right)$ Laboratoire de Physique des Gaz et des Plasmas, Université Paris-Sud, Bâtiment 212, 91405 Orsay Cedex, France

(4) Department of Plysics, University of Cape Town, 7700 Rondebosch, South Africa

(Received 16 July 1991, revised 12 November 1991, accepted 19 November 1991)

\begin{abstract}
A Coherent Anti-Stokes Raman Spectroscopy (CARS) study of the hydrogen plasma generated by a discharge with magnetic multipolar confincment has been conducted at pressures in the range 0.5-5 $\mathrm{Pa}$. The steady-state radial distribution of the rovibrational populations has been measured. The vibrational temperature is always uniformly distributed and so is the rotational temperature at the lower pressures, while a strong gradient is scen at $5 \mathrm{~Pa}$ for the rotation. Time-resolved measurements with the discharge operated in a square-pulse mode give additional insight into the dynamics of the discharge. Some results are compared with the predictions of two computer models of the plasma kinetics. We observe $\mathrm{H}_{2}$ vibrational excitation by the Joule-heated filament alone (in the absence of the discharge) and show it to be caused primarily by the confined discharge between the filament and its cold positive copper connector. Another interpretation of the presence of vibrationally excited $\mathrm{H}_{2}$ by recombinative desorption (Hall R.I. et al., Phys. Rev. Lett. 60 (1988) 337) is not comforted by our results, within instrumental sensitivity. The densitics of the first rotational levels reveal that the ortho and para forms of $\mathrm{II}_{2}$ have different clectron collisional cross-sections. Under pulsed excitation, the vibrational temperature rises on a time scale of 1-2 ms in agreement with numerical predictions. $\Lambda$ switch-off, we show by matching the experimental and theoretical decays that vibrational state $v=1$ survives $16 \pm 5$ wall collisions; meanwhile, the rotation cools very rapidly, probably because of superclastic clectronic collisions.
\end{abstract}




\section{Introduction.}

Magnetic-multipolar hydrogen plasmas have received considerable attention for positive and negative ion production [1-10]. The kinetic behaviour of these plasmas remains difficult to study. The traditional optical methods with good sensitivity like fluorescence, which are delicate to apply to hydrogen because very short wavelengths are needed [11] here fail because of the intense background emitted by the discharge. Three other methods have been tried recently with mixed success. The first one is Coherent anti-Stokes Raman Scattering [12], or CARS, which has already given some insight into the problem $[13,14]$, but does not have the sensitivity required to detect the highest vibrational states. Recently, multiphoton ionization has also been used $[4,5,15]$. The latter is more sensitive, but does not permit in situ measurements because the discharge interferes with the collection of the ionization current. Also promising [6], is straight VUV absorption, which shows good sensitivity on atoms, but lacks spatial resolution. This paper reports on the continuation of our CARS research effort [13, 14]. The emphasis has been placed on the dynamics of the plasma.

It is useful to review some facts about our preceding study. The reactor had a volume of about $2 \mathrm{dm}^{3}$ and was operated at a pressure of $5.3 \mathrm{~Pa}(40 \mathrm{mTorr})$ under a $90 \mathrm{~V}, 10 \mathrm{~A}$ discharge. Several findings regarding neutral species posed delicate questions. The medium was found to be highly displaced from Boltzmann equilibrium:

1 - rotational equilibrium in the first four-five rotational states is indeed established, at a temperature of $550 \mathrm{~K}$ typically;

2 - however, higher rotational states rapidly deviate from the Boltzmann law as $J$ increases;

3 - this rotational distribution is the same for the vibrational states $v=0-2$ within measurement error;

4 - the vibrational states follow the Boltzmann law up to $v=3$, highest state detected, and the vibrational temperature is about $2500 \mathrm{~K}$;

5 - the $\mathrm{H}_{2}$ density corresponds to a partial pressure of only $70 \%$ of the total pressure as a cónsequence of dissociation and ionization;

6 - the pressure balance is contributed for the most part by atoms at low density, but high temperature; the latter, originally assessed to be $\approx 0.4 \mathrm{eV}$, was subsequently corrected and placed $[16,17]$ at $\approx 0.25 \mathrm{eV}$.

Some of the key figures are grouped in table $I$.

Table I. - Main results concerning $\mathrm{H}_{2}$ molecules and electrons from reference [14] and $\mathrm{H}$ atoms from references [14] and [17], at 5.3 $\mathrm{Pa}$ and $10 \mathrm{~A}$ discharge current.

\begin{tabular}{|cccc|cc|cc|}
\hline \multicolumn{3}{|c|}{$\mathrm{H}_{2}$} & \multicolumn{2}{|c|}{$\mathrm{H}$} & \multicolumn{2}{c|}{ electrons } \\
\hline $\begin{array}{c}\text { density } \\
T_{\text {rot }}\end{array}$ & $T_{\text {vib }}$ & $p_{\mathrm{H}_{2}}$ & density & temperature & density & temperature \\
$\left(10^{14} \mathrm{~cm}^{-3}\right)$ & $(\mathrm{K})$ & $(\mathrm{K})$ & $(\mathrm{Pa})$ & $\left(10^{13} \mathrm{~cm}^{-3}\right)$ & $(\mathrm{K})$ & $\left.\mathrm{cm}^{-3}\right)$ & $(\mathrm{K})$ \\
5.4 & 530 & 2390 & 3.9 & 4.6 & 2700 & 1 & 9400 \\
\hline
\end{tabular}

Several aspects of the preceding results were striking. First, the rotational distribution deviates strongly from the Boltzmann equilibrium (point 2). In effect, the curvature in the 
Boltzmann plot of populations is considerable, showing a temperature excursion from $550 \mathrm{~K}$ at low $J$ to $5000 \mathrm{~K}$ measured using $J=9$ and 11 . The excess population in the high energy states was attributed to the vibrational deactivation of molecules at the wall, e.g. $\mathrm{H}_{2}(J=$ $1, v=1) \longrightarrow \mathrm{H}_{2}(J=9, v=0)$. The high rotational states must have smaller volume- and walldeactivation rates for their excess rotational energy. Thus they experience relatively longer lifetimes than the lower states within a given vibrational manifold. Another mechanism, the direct pumping into high energy rotational states, i.e. with $\Delta J=4-10$, probably also plays a role. This could occur in collisions with electrons and atoms. The latter are known to possess high kinetic energy, in the range $\approx 0.2-0.6 \mathrm{eV}$, in similar plasmas $[6,14,17]$. Such atoms have been shown to cause substantial vibrational pumping and atom-exchange reactions [18], and they also might create high rotational excitation. However, this last point is not firmly established to our knowledge, and available data [19] seem to indicate that the phenomenon is weak. Second, the role of wall deactivation of neutral species was suspected to be crucial, but difficult to assess quantitatively. Specifically, one was concerned that wall effects would induce gradients in the reactor and the probe volume, causing measurement errors [20]. The mean free path $\ell$ (Tab. II) is calculated from cross-sections taken from the compilation of Phelps [21] at the pressure and temperature which prevail in the reactor. It is small enough compared with the reactor diameter $(1 \mathrm{~cm}$ vs. $16 \mathrm{~cm}$, respectively) that large differences in densities and temperatures could develop between center and edges of the plasma; indication of this fact was suggested by comparison of results obtained with good spatial resolution, i.e. with the BOXCARS [22] beam geometry, and with poor resolution, i.e. with collinear beams.

Table II. - Diffusion constant $D$, mean velocity $v=0.92 \sqrt{\frac{3 R T_{\mathrm{t}}}{m}}$ and mean free path $\ell$ for $\mathrm{H}_{2}$ under conditions of table $I$ ( $R$ : ideal gas constant and $m$ : molar mass).

\begin{tabular}{|c|c|c|}
\hline $\begin{array}{c}D \\
\left(\mathrm{~m}^{2} \mathrm{~s}^{-1}\right)\end{array}$ & $\begin{array}{c}v \\
\left(\mathrm{~ms}^{-1}\right)\end{array}$ & $\begin{array}{c}\ell \\
(\mathrm{cm})\end{array}$ \\
\hline 5.6 & 2400 & 1 \\
\hline
\end{tabular}

New results have now been obtained and are presented here. A short review of the experimental procedures is given in section 2 , then two distinct and complementary sets of measurements are described in section 3. First, radial distributions of the rotational and vibrational temperatures in a steady-state discharge are shown and discussed. Second, the rise and fall of the rotational and vibrational populations at switch-on and after switch-off of a square discharge pulse have been monitored and interpreted. Comparison of some of the experimental results with numerical simulations of the plasma transients was conducted to facilitate analysis and to extract data about wall deactivation of molecules in state $v=1$.

\section{Experimental setup and data analysis.}

The experimental setup has been described elsewhere [13, 14, 23, 24]. We recall that the rovibrational populations of $\mathrm{H}_{2}$ molecules exposed to a magnetically confined discharge are measured using CARS as a non-intrusive optical diagnostic. The discharge is produced in a 
$16 \mathrm{~cm}$-diam, $20 \mathrm{~cm}$-long cylindrical copper chamber, serving as the anode, cooled to $220 \mathrm{~K}$ and mounted vertically under a bell jar. The magnetic multicusp arrangement is produced by means of 12 ceramic magnets attached to the outside chamber wall. The discharge is created by thermionic electrons emitted by two $0.5 \mathrm{~mm}$-diam, $10 \mathrm{~cm}$-long, thoriated tungsten filaments which are Joule- heated; these filaments are connected in parallel and mounted side by side. They are placed near the axis of the chamber. One of their ends is grounded. The positive voltage $(90 \mathrm{~V})$ is applied to the copper wall of the chamber. The main innovation with respect to the previous $\mathrm{H}_{2}$ plasma experiment [14] is that the discharge can be pulsed if necessary for kinetics studies; the positive voltage applied to the wall then can be switched on and off using a pulse generator which gives a square $90 \mathrm{~V}$ pulse. The pulses are delivered by a capacitor bank switched by a thyratron. They have a duration which is deliberately limited to $1 \mathrm{~ms}$ so that only $5 \%$ of the stored charge is removed, which guarantees good stability of the discharge voltage. The rise and fall times are $10 \mu \mathrm{s}$. The pulses are repeated at a rate compatible with the CARS laser firings. Their timing is controlled by a clock running at $5 \mathrm{~Hz}$, which also triggers the laser after an adjustable delay. The discharge current is set at $10 \mathrm{~A}$ in all cases. This is achieved by adjusting the filament current; depending on the $\mathrm{H}_{2}$ gas pressure and on the filament characteristics, both for continuous and pulsed discharge operations, the current per filament falls in the range 18-20 A.

The $\mathrm{H}_{2}$ gas is introduced at the bottom of the generator through a small injector. The tests were conducted for two values of the pressure, namely 5.3 and $0.53 \mathrm{~Pa}$. The pressure is monitored in the bell jar, but outside of the generator, by means of an MKS Baratron gauge. The flow rate is $0.23 \mathrm{~cm}^{3} \mathrm{~s}^{-1}$ at standard temperature and pressure, or $4.4 \mathrm{dm}^{3} \mathrm{~s}^{-1}$ at the pressure of $5.3 \mathrm{~Pa}$. These figures are to be compared to the generator's volume of $5 \mathrm{dm}^{3}$ and to the bell jar's $\left(40 \mathrm{dm}^{3}\right)$. The operation of the discharge is done at pressures which are comparable to or one order of magnitude larger than those used for $\mathrm{H}^{-}$production. In practice, this is acceptable for our kinetics studies.

The CARS setup is basically unchanged with respect to the previous studies $[13,14]$. However, these prior experiments had shown that density and/or temperature gradients were present in the reactor and that the spatial resolution afforded by the usual, more sensitive collinear beam arrangement was inadequate [14]. Thus, the BOXCARS [21] optical configuration, which offers better spatial resolution at a cost of a factor of 5 - 10 in sensitivity, has to be used, and most of the results presented here are obtained with it, unless specified otherwise. The probe volume is $\approx 3 \mathrm{~cm}$ long and $150 \mu \mathrm{m}$ in diameter, with an appreciable fraction of the signal coming from a shorter $1-2 \mathrm{~cm}$-long segment. The axis of this probe volume is kept fixed in space and positioned so as to intercept the generator axis near the center, and 4 $\mathrm{cm}$ below the filaments. The probe volume can be moved along this line of sight in order to explore the radial distributions. This is done by translating the focussing and recollimating lenses. The total travel of the lenses is about $8 \mathrm{~cm}$, which allows one to explore a little more than one full radius of the generator. The triggering is performed using a clock as explained above. Because the Nd:YAG laser is passively Q-switched, the jitter between the leading edge of the discharge pulse and the laser pulse $(\approx 10 \mathrm{~ns}$ duration) is typically $\pm 10 \mu \mathrm{s}$. This jitter is very short compared with the characteristic times of all the transient phenomena studied here.

For the lineshape reduction and data analysis, we use the procedures introduced and validated previously [14], with a few minor changes. However, since this is a delicate aspect of the experiments, some discussion is here necessary. We first note that quantum state densities are now obtained by calculating the integrated areas of the lines over a spectral window of $0.05 \mathrm{~cm}^{-1}$. This method of data reduction is more accurate than merely measuring peak intensities as we did before, because it minimizes the incidence of laser power fluctuations and the errors caused by uncertainties in laser and molecular linewidths. We also observe that the 
instrumental spectral resolution is not sufficient to fully resolve the CARS lines, which are Doppler-broadened in this plasma. This shortcoming is frequent in CARS applications and poses a problem because the true molecular line contour and/or the static temperature must be known for proper data reduction.

It is then customary to take for the translational temperature $T_{\mathrm{t}}$ the value of the rotational temperature, $T_{\text {rot }}$, which is generally the same and can be measured with fair accuracy. Thus, our initial approach here has been to take for $T_{\text {rot }}$ the value given by a Boltzmann diagram of the populations of the first four rotational states. This approach is based on the assumption that these states have low energies and must equilibrate rapidly, i.e. in a few gas-kinetic collisions, with the translation. One must point out that the populations plotted in the abovementioned Boltzmann diagram are not known accurately a priori because $T_{t}$ is not known precisely yet. However, the measurement error which affects these populations is the same for the four states since the corresponding four rotational lines have identical widths and contours, being very close to each other spectrally. Therefore, the rotational temperature is derived from the Boltzmann diagram with good accuracy. The state densities can subsequently be rederived in a second, more accurate iteration based on the exact value of $T_{t}$. We shall see in the next section that this approach requires some refinements.

\section{Results.}

Two classes of experiments were conducted:

(i) measurement of radial profiles of temperature and $\mathrm{H}_{2}$ quantum-state populations with a continuous discharge;

(ii) monitoring of rise and decay of temperatures and densities following switch-on and then switch-off of a 1 ms-long square discharge pulse.

Both types of experiments give insight into the dynamics of the plasma. Most of the data were collected at a pressure of 5.3 $\mathrm{Pa}$, which is higher than the normal operating conditions for this sort of plasma [2], but remains amenable to CARS density measurements. Occasionally, measurements were also taken at the pressure of $0.53 \mathrm{~Pa}$ to complement the results in a regime where the molecular mean free path $(\approx 6 \mathrm{~cm}$ for this case) becomes comparable with the reactor size; this reduces the impact of diffusion and leaves the molecular kinetics dominated by wall collisions.

\subsection{CONTINUOUS DISCHARGE.}

3.1.1 Rotation. - Our previous measurements [14] had shown the first five rotational states to be populated according to the Boltzmann law in the discharge. We have verified this point using BOXCARS for good spatial resolution. The new results, while roughly confirming the old ones, actually reveal some unexpected effects (Fig. 1). An apparent breakdown of the 1 to 3 ratio of populations between the para and ortho forms of $\mathrm{H}_{2}$ is observed systematically at $5.3 \mathrm{~Pa}$. The data are presented for the position $r=5 \mathrm{~cm}$ from the generator axis. A population defect of about $20 \%$ is seen in the para densities for states $J=0$ and 2 (or, equivalently, an excess in ortho states $J=1$ and 3 ) of $v=0$. The effect is seen in this figure to be even more pronounced in $v=1$ with state $J=2$ (unfortunately, $J=0$ is below detection limit). This phenomenon is not an artefact, although the difference is barely in excess of instrumental detection error, viz. $\approx \pm 5 \%$. An example of the typical data precision is given by the Boltzmann plot obtained without discharge, where the data point alignment is near perfect. In that case, one finds from the slope a temperature of $231 \pm 2 \mathrm{~K}$, which is close to 
the temperature of the circulating wall coolant $(223 \mathrm{~K})$. Note in passing that the measurement accuracy quoted $( \pm 2 \mathrm{~K}$ ) is the accuracy given by the least-mean-squares routine used to derive the rotational temperature from the Boltzmann plots. This accuracy was also demonstrated to be equal to the standard deviation of half a dozen temperature measurements taken under the same conditions. Finally, one notes that, if the temperatures found for the ortho and para forms in the discharge are here equal within instrumental error, viz. 512 and $518 \mathrm{~K}$ respectively, one frequently finds the value to be slightly larger for the para.

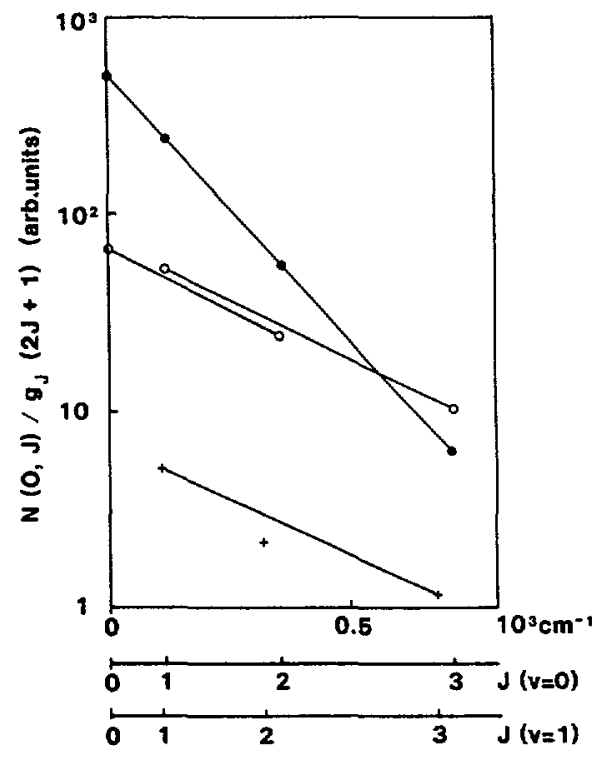

Fig. 1. - Boltzmann diagram of rotational populations of $v=0(0)$ and $v=1(+)$ at $5.3 \mathrm{~Pa}$ and position $r=5 \mathrm{~cm}$ in the generator, with discharge, and for $v=0$ without discharge and filament heating ( $\bullet), g_{j}$ is the nuclear spin factor. Horizontal scales give energies and markers for rotational state positions in $v=0$ and 1.

The apparent population discrepancy may have several causes:

a) instrumental artefacts caused by changes in laser linewidth or by the presence of some background interference; these effects, however, have been experimentally ruled out.

b) The temperature and density gradients in the probe volume also lead to population measurement biasing because of the spatial integration in the probe volume [20]. However, this biasing cannot explain the observed anomaly. If two homogeneous zones separated by a sharp boundary are probed, the Boltzmann diagram shows two distinct distributions for the low $J$ values and for the high ones, with well-defined temperatures, i.e. those of the two homogeneous zones, and connected by a smooth curve. There is no visible ortho/para intensity alternation. This is illustrated in figure 2 , which presents the results of a numerical simulation of $\mathrm{H}_{2}$, assuming that half of the probe volume is immersed in a $300 \mathrm{~K}$ sample and the other half in a $600 \mathrm{~K}$ sample.

c) Another possible cause is the difference in diffusivity of the ortho and para species, which might cause wall deactivation to be less pronounced for one of the species. This phenomenon is not large, however, and is only noticeable at low temperatures, e.g. $5-50 \mathrm{~K}$ [25]. 


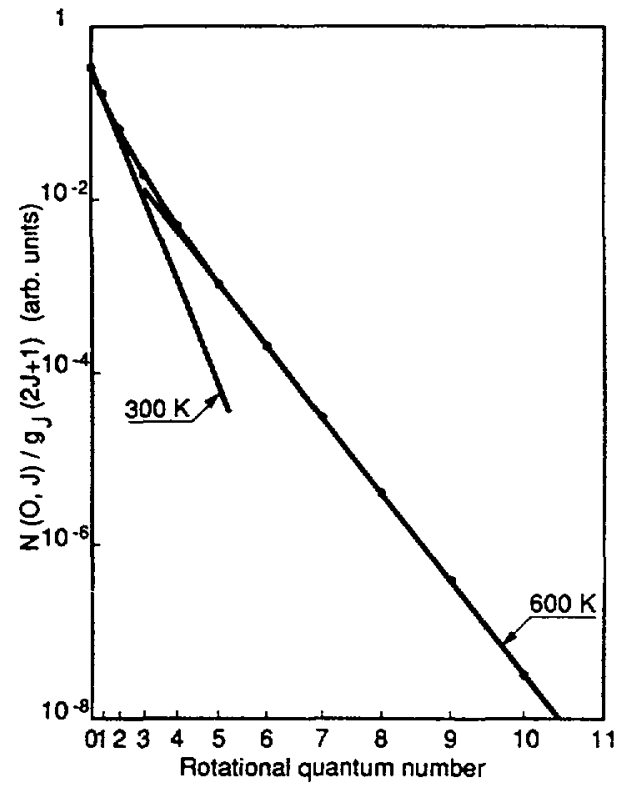

Fig. 2. $-\mathrm{H}_{2}$ rotational population distribution computed with probe volume half immersed in a $300 \mathrm{~K}$ sample and half in a $600 \mathrm{~K}$ sample.

d) The most probable explanation of the ortho/para anomaly is that low-energy electronic collisions cause the population to climb up the ladder of rotational states, and that the pumping rate is faster in the para form, in part because its rotational states are more closely spaced. It has been shown theoretically and also experimentally that, for the range of energies 1 $10 \mathrm{eV}$, the rotational-excitation cross-section is 50-100\% larger for the para form than for the ortho [26]. Confirmation of these experimental results and of the interpretation based on the difference in ortho/para electron collision cross-sections will be given in the transient experiments.

In view of the results of figure 1 , it has been decided to take for $T_{\text {rot }}$ and $T_{\mathrm{t}}$ the $T_{\text {rot }}$ value found from the populations of the odd states $J=1$ and 3 which are always easily detected, rather than the result of a least-squares fit to the states $J=0-3$. In vibrational state $v=1$, $T_{\text {rot }}$ is similarly derived from $J=1$ and 3 only.

Temperature profiles obtained for $v=0$ and 1 in the $5.3 \mathrm{~Pa}$ case are plotted vs. distance $r$ from the generator axis in figure 3 , and in figure 4 for the $0.53 \mathrm{~Pa}$ case. Since the travel of the focussing optics is limited, the data could not be recorded over the full diameter of the reactor. Several conclusions are deduced from these profiles:

1 - the rotational temperature is not uniform, as had been suspected in previous investigations [14]. This is attributed to the combination of cooling on the plasma boundaries by the walls and heating throughout the volume by collisions with electrons, ions and atoms, the electrons being probably the main agent of excitation. The phenomenon is more pronounced at 5.3 than at $0.53 \mathrm{~Pa}$. This is not surprising because the mean free path $\ell$ (Tab. II) is, in the latter case, comparable to the reactor radius $(6 \mathrm{~cm}$ vs. $8 \mathrm{~cm}$, respectively). In other words, the "heat conductivity" to the walls is then higher.

2 - The rotational temperature in state $v=1, T_{\text {rot }}(v=1)$, is significantly higher than that in $v=0, T_{\text {rot }}(v=0)$. This is quite pronounced near the center of the generator, as shown in 


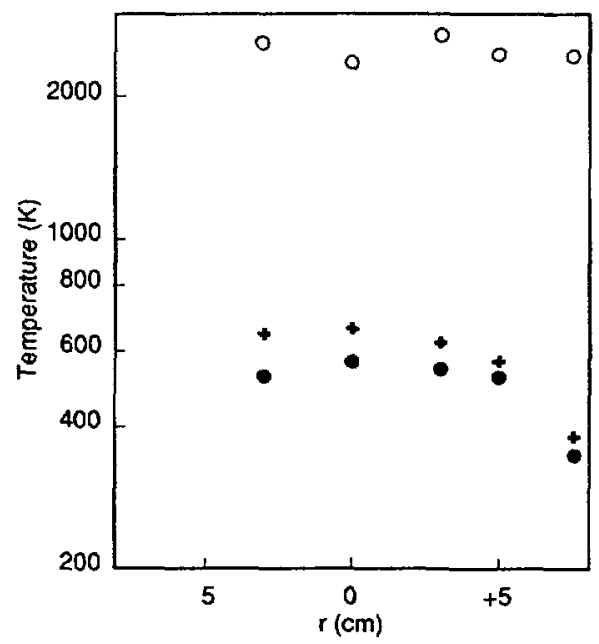

Fig. 3. - Radial distribution of rotational temperatures in vibrational states $v=0(\bullet)$ and $v=1(+)$, and of vibrational temperature (o) as determined from the ratio of populations in these two states; pressure: $5.3 \mathrm{~Pa}$.

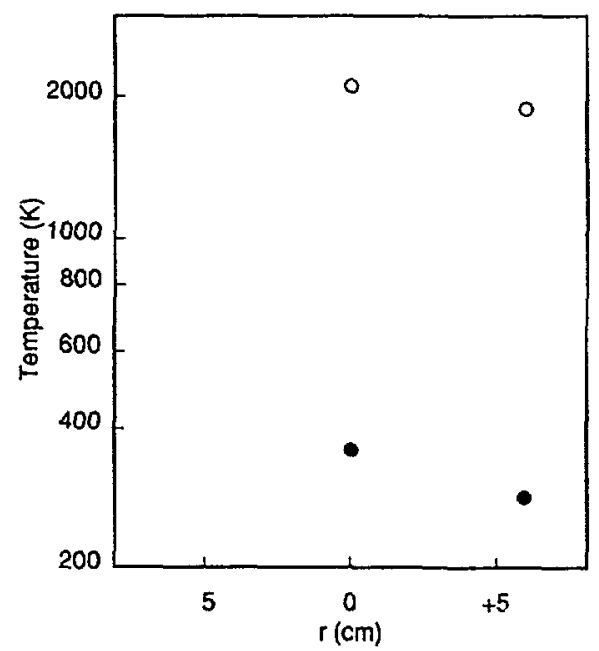

Fig. 4. - Radial distribution of temperatures at $0.53 \mathrm{~Pa}$ : (•) rotational temperature in $v=0$; (o) vibrational temperature.

figure 3 ( 650 vs. $550 \mathrm{~K})$.

This result requires some discussion.

a - It can be explained in part by a difference in pure rotational pumping (i.e. of the type $\Delta v=0, \Delta J \geq 2$ ) of the two states by the electrons, because the rotational levels in $v=1$ have closer spacing $\left(B_{1}=56.3 \mathrm{~cm}^{-1}\right)$ than those of $v=0\left(B_{0}=59.3 \mathrm{~cm}^{-1}\right)$. It is likely that the rotational- excitation cross-section is larger in $v=1$ than $v=0$ because the electronic charge 
distribution is more elongated.

b - Rotational-vibrational heating by electrons causing transitions like:

$$
\mathrm{H}_{2}(v=0, J)+\mathrm{e} \longrightarrow \mathrm{H}_{2}(v=1, J+\Delta J)+\mathrm{e}, \quad \text { with } \Delta J \geq 2
$$

must play a role. The cross-section for the process with $\Delta J=2$ is quite significant [27] in the collision energy range $1-10 \mathrm{eV}$. One may therefore suspect that this is one of the prime causes for the rotational temperature to be larger in $v=1$ than in $v=0$.

c - The phenomenon can also be explained by a quasi-resonant rotation- rotation (R-R) pumping mechanism, causing rotational population transfer from the vibrational state $v=0$ to the state $v=1$, also because of the different rotational level spacings which make the reaction:

$$
\mathrm{H}_{2}(v=1, J)+\mathrm{H}_{2}(v=0, J+2) \longrightarrow \mathrm{H}_{2}(v=1, J+2)+\mathrm{H}_{2}(v=0, J)
$$

exothermic. Similar phenomena are well-known in vibrationally excited gases and lead to anharmonic $\mathrm{V}-\mathrm{V}$ pumping [28] and to selective energy transfers in quasiresonant vibrational modes, e.g. in the $\mathrm{N}_{2}-\mathrm{CO}_{2}$ or the $\mathrm{N}_{2}-\mathrm{CO}$ discharge lasers [29]. These processes are observed in molecular systems when the translational temperature is different from the vibrational temperature. For the harmonic oscillator case, a closed-form expression between the relevant temperatures is easily derived [29]. Unfortunately, there exists, to our knowledge, no closed-form equation linking $T_{\mathrm{t}}$ and the $T_{\text {rot }}$ values of two near-resonant rotors. Thus, one should resort to computer calculations based on state-to-state rotational transfer rates. Some of the rates are already known [30-32] for $\mathrm{H}_{2}$ (Tab. III). We have not attempted to perform these calculations, but did examine if $R-R$ pumping is effective in our plasma [33]. By comparing the distance travelled by molecules between rotational inelastic collisions during time $\tau \approx 1 / k n$ (with $k$ rate constant as given in Tab. III and $n$, density as given in Tab. I) to the reactor size, we conclude it to be negligible here. At pressures higher than those used in this study, for instance $10 \mathrm{~Pa}$ or more, one would certainly have to pay due consideration to R-R pumping. If this process was able to develop, then one would have $T_{\mathrm{t}}<T_{\text {rot }}(v=0)$ by analogy with the V-V pumping results, and our assumption of section 2 that these two temperatures are equal should be revised.

Table III. - Comparison of rotational energy transfer rates in $\mathrm{H}_{2}$, in units of $10^{6} \mathrm{~s}^{-1}$ amagat $\left(=3.72 \times 10^{-14} \mathrm{~cm}^{3} \mathrm{~s}^{-1}\right)$. Reverse rates $\left(k_{2 \rightarrow 0}\right.$ and $\left.k_{3 \rightarrow 1}\right)$ are obtained from detailed balance.

\begin{tabular}{|cc|cc|}
\hline$v=0$ at $300 \mathrm{~K}^{(\mathrm{a})}$ & \multicolumn{2}{|c|}{$v=1$ at $295 \mathrm{~K}^{(\mathrm{b})}$} \\
\hline$k_{0 \rightarrow 2}$ & $k_{1 \rightarrow 3}$ & $k_{0 \rightarrow 2}$ & $k_{1 \rightarrow 3}$ \\
95 & 6.5 & $180 \pm 27$ & $50 \pm 8$ \\
\hline
\end{tabular}

(a) Rates within state $v=0$, from reference [32], based on the results of reference [30]. (b) Rates for $v=1$ in a bath of $v=1$ molecules, from reference [32].

3 - Near the walls of the generator, the temperatures in $v=0$ and $v=1$ are lower and become equal within experimental error ( 353 and $360 \mathrm{~K}$, respectively). This is a consequence of translational-rotational cooling by the wall. We observe that, because the gas is approximately $100 \mathrm{~K}$ hotter than the wall at a distance of the order of one mean free path or less, 
the accommodation must be incomplete. In fact, the wall is mainly covered with tungsten evaporated from the filament, and, for tungsten, the accommodation coefficient of $\mathrm{H}_{2}$ is in the range $0.06-0.2$ according to several authors [34]. Two of us also have measured this coefficient and found 0.1 for a polycrystalline surface at $1170 \mathrm{~K}[35]$.

3.1.2 Vibration. - The figure 3 also presents the radial profile of the vibrational temperature, $T_{\text {vib. }}$. The latter is determined from the two states $v=0$ and 1 , which are the only states detectable using BOXCARS under these conditions. This, however, is sufficient for determining a temperature applicable to the states $v=0-3$, since our previous work [14] has shown that the vibrational population distribution obeys the Boltzmann law up to $v=3$; Young and coworkers [36] have confirmed this to hold up to $v=8$. Other recent results, obtained however with hot filaments but without the main discharge, seem to indicate that the higher states could depart from it [37]. The radial distribution is seen to be uniform, which is at variance to the behaviour of the rotation. This difference is significant. It indicates that the deactivation of vibration at the walls is not as rapid as the other volume-distributed mechanisms of excitation and loss. These mechanisms have been compiled in the communications of Gorse and coworkers $[38,39]$. The volume loss mechanisms in $v=1$ are, among others:

1 - dissociation and dissociative attachment, both of which are weak processes.

2 - the quasi-resonant reaction:

$$
\mathrm{H}_{2}(v=1)+\mathrm{H}_{2}(v=1) \Longleftrightarrow \mathrm{H}_{2}(v=0)+\mathrm{H}_{2}(v=2)
$$

which normally restores Boltzmann equilibrium.

3 - The very effective inelastic collisions with H-atoms (V-T exchange):

$$
\mathrm{H}_{2}(v=1)+\mathrm{H} \longrightarrow \mathrm{H}_{2}(v \neq 1)+\mathrm{H}
$$

With their kinetic energies of $\approx 0.3 \mathrm{eV}[14,16,17]$, the latter have a large cross-section in collisions with $\mathrm{H}_{2}$ for atom exchange $[18,38]$ (reactive collisions) and for causing straight vibrational population change without atom exchange (non-reactive collisions). The rates for V-T exchange in $\mathrm{H}_{2}-\mathrm{H}$ collisions have been calculated by Lagana [38]. These rates are given in table IV assuming that the temperature is $1500 \mathrm{~K}$ for both species, which yields a fair representation of the relative motion of the $2700 \mathrm{~K}$ atoms and $550 \mathrm{~K}$ molecules (see Tab. I). Some interpolations had to be made using the tables at 500,1000 and $4000 \mathrm{~K}$ given in reference [38]. With a net rate constant of $k_{\mathrm{V}-\mathrm{T}} \approx 0.5 \times 10^{-10} \mathrm{~cm}^{3}$ atom $\mathrm{m}^{-1} \mathrm{~s}^{-1}$ out of $v=1$, the lifetime of state $v=1$ calculated using the $H$ density reported in table $I$ is only $4.4 \times 10^{-4} \mathrm{~s}$ at $5.3 \mathrm{~Pa}$.

Table IV. - Reactive (with atom exchange) and non-reactive vibration-vibration rate constants in units of $10^{-12} \mathrm{~cm}^{3}$ atom ${ }^{-1} \mathrm{~s}^{-1}$, for $\mathrm{H}+\mathrm{H}_{2}(v=1) \longrightarrow \mathrm{H}+\mathrm{H}_{2}\left(v^{\prime}\right)$ at translational temperature $1500 \mathrm{~K} .^{(\mathrm{a})}$

\begin{tabular}{|c|c|c|c|}
\hline & $v^{\prime}=0$ & $v^{\prime}=1$ & $v^{\prime}=2$ \\
\hline non-reactive & 10 & 150 & - \\
reactive & 14 & 22 & 3 \\
\hline
\end{tabular}

(a) Reference [38]; although $\mathrm{H}$ is at a translational temperature of $\approx 2700 \mathrm{~K}$ in the discharge, one must bear in mind that $\mathrm{H}_{2}$ is at $550 \mathrm{~K}$ only; to reflect relative motion in center of mass of $\mathrm{H}+\mathrm{H}_{2}$ system, we calculate rate constants from their tables 2-9 using an interpolation. 
4 - The very effective electronic collisions (e-V collisions):

$$
\mathrm{H}_{2}(v=1)+\mathrm{e} \longrightarrow \mathrm{H}_{2}(v \neq 1)+\mathrm{e} .
$$

The corresponding rates have been computed by Wadehra [40]. Those pertinent to $v=1$ are given in table $\mathrm{V}$ for $1 \mathrm{eV}$ electrons. The sum of those out of $v=1$ yields a rate constant $k_{\mathrm{e}-\mathrm{V}}(v=1)=1 \times 10^{-9} \mathrm{~cm}^{3}$ electron ${ }^{-1} \mathrm{~s}^{-1}$. Given the electron density of $n_{\mathrm{e}}=10^{12} \mathrm{~cm}^{-3}$, the lifetime of state $v=1$ imposed by electrons alone is about $1 \mathrm{~ms}$. This lifetime is comparable to that imposed by atomic collisions (Eq. (4)). Finally these results are in reasonable agreement with those recently computed by Bacal et al [41].

Table V. - Rate constants in units of $10^{-9} \mathrm{~cm}^{3}$ electron ${ }^{-1} \mathrm{~s}^{-1}$ for reaction $\mathrm{H}_{2}(v)+\mathrm{e} \longrightarrow$ $\mathrm{H}_{2}\left(v^{\prime}\right)+\mathrm{e}$.

\begin{tabular}{|c|c|c|c|}
\hline$v^{v^{\prime}}$ & 0 & 1 & 2 \\
\hline 0 & 49.2 & 0.16 & - \\
1 & 0.45 & 56.1 & 0.48 \\
\hline
\end{tabular}

It is quite interesting to compare the net resulting "volume" lifetime imposed by the combined action of atomic and electronic collisions, viz about $0.3 \mathrm{~ms}$, to the sole effect of the walls. We shall see below that the "wall vibrational lifetime" at $0.53 \mathrm{~Pa}$ is of the order of $1.5 \mathrm{~ms}$ after discharge switch-off, which is significantly longer than the "volume lifetime". This is consistent with the fact that the radial distribution of $T_{\mathrm{v}}$ is found to be flat at both $5.3 \mathrm{~Pa}$ and $0.53 \mathrm{~Pa}$, as shown in figure 4 . It is also interesting to point out that the lifetime of state $v=1(\approx 0.3 \mathrm{~ms})$ is of the same order of magnitude as the lifetimes of any of the first four rotational levels of $v=0$ (see Sect. 3.1.1, Tab. III).

3.1.3 Number density and pressure. - The $\mathrm{H}_{2}$ number density is derived from the CARS line intensities (Sect. 2). It is obtained by summing the number densities of all the rotational states in the $v=0$ vibrational manifold. Appropriate corrections for the undetected states are made. The densities of molecules in vibrational states $v>0$ are also calculated and added to that of $v=0$. This calculation is based on the assumption that the vibrational populations follow the Boltzmann law. All these corrections remain small, i.e. a total of less than $10 \%$.

The resulting density profile $N(r)$ is shown in figure $5 \mathrm{a}$ for the $5.3 \mathrm{~Pa}$ case. As expected, this profile shows the density to increase where the static temperature is lower, i.e. close to the walls. Also shown is the partial pressure of $\mathrm{H}_{2}$ molecules, $p_{\mathrm{H}_{2}}(r)$, which is proportional to the product $N(r) \times T_{\mathrm{t}}(r)$, where we take $T_{\mathrm{t}}(r)=T_{\text {rot }}(v=0, r)$ (Fig. $\left.5 \mathrm{~b}\right)$. The pressure profile is found to be flat within experimental error. Uncertainties are larger than for $N(r)$ or $T_{\mathrm{t}}(r)$ alone, since $p_{\mathrm{H}_{2}}(r)$ is proportional to their product. We also note that $p_{\mathrm{H}_{2}}(r)$ is about $70 \%$ of the pressure of $5.3 \mathrm{~Pa}$ which is maintained in the bell jar (the latter pressure is read by the Baratron gauge at a point outside the generator). This phenomenon had been reported previously [14]. It can be explained by dissociation. Dissociation of $15 \%$ of the molecules would cause the observed drop in $\mathrm{H}_{2}$ partial pressure, assuming the $\mathrm{H}$ and $\mathrm{H}_{2}$ species had the same translational temperature. However, several reports reveal that the dissociation is less than 
$15 \%$ in similar reactors $[6,14,17,42]$. One therefore concludes that the translations of $\mathbf{H}$ and $\mathrm{H}_{2}$ do not obey the Boltzmann equilibrium or that their velocity distribution functions do not follow the Maxwell-Boltzmann law. This is also suggested by the non-Boltzmann character of the rotation and of the vibration in $\mathrm{H}_{2}$. If, for instance, the velocity distribution of $\mathrm{H}_{2}$ had a broad, high energy tail, the CARS lines would present weak, broad wings; such wings are hard to detect and some of the molecular population would remain undetected. NonMaxwellian distributions have already been reported in such plasmas [6,43]. In addition to this phenomenon, coexistence of translationally cold molecules and hot atoms is a possibility. In the previous study [14] we brought evidence based on Balmer $\beta$ emission spectroscopy of this coexistence; Stutzin et al. [6] confirmed this result using VUV absorption spectroscopy.
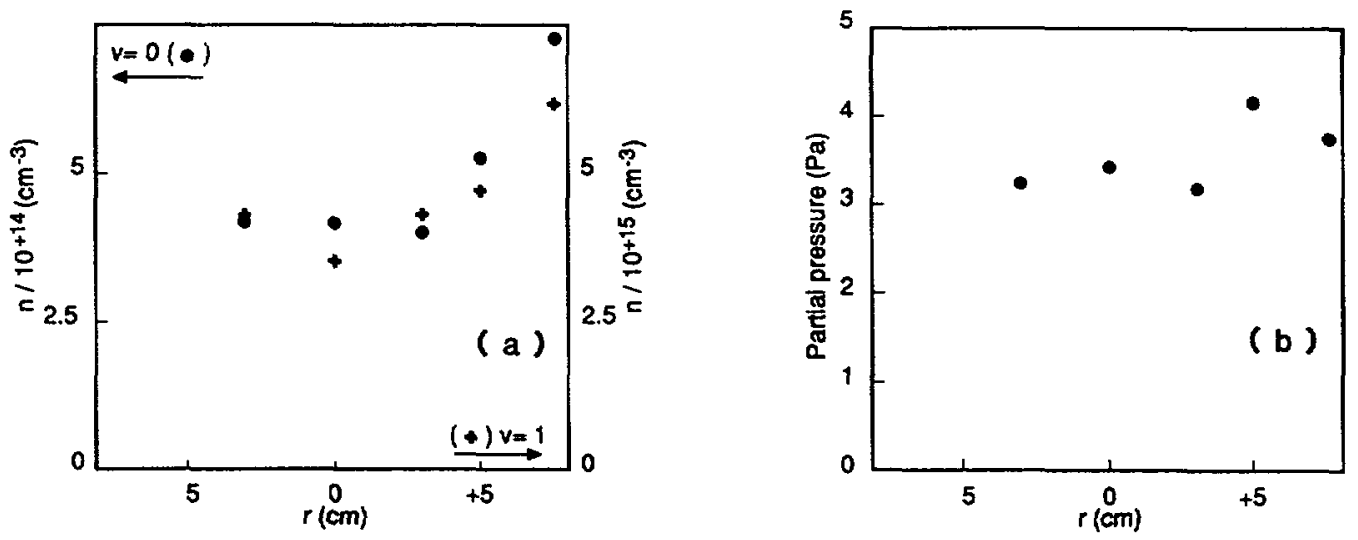

Fig. 5. - Radial distribution of number densities in $v=0$ and $v=1$ (a), and $\mathrm{H}_{2}$ partial pressure (b).

3.2 PUlSED DISCHARGE. - Measurements performed with the pulsed discharge provide additional insight. The spectra have been collected by repetitively firing the CARS set up at fixed delays with respect to the leading edge of the discharge pulse. The parameters of interest have been monitored through the entire duration of the pulse, as well as before and after it. The time evolutions of the rotational and vibrational temperatures and of the density have been followed at the center of the generator and near the wall. For clarity, the results are presented at switch-on (thus revealing mostly the kinetics resulting from electron excitation), and then switch-off, showing the effects of collisional relaxation and transport of rotational and vibrational energies to the walls with considerably reduced density and activity of the charged species.

The transients at switch-on and switch-off also provide excellent opportunities for testing computer models of the plasma because only a limited number of physical processes are at play to bring the system to its new equilibrium, especially at switch-off; rate constants are more easily calculated. Conversely, the models can also be employed to assist in the data analysis, particularly by showing which phenomena are important. Two models have been employed :

- a simple model (model 1) developed at Laboratoire de Physique des Gaz et des Plasmas which assumes the plasma to be homogeneous, the rotational and vibrational temperatures to be constant as well as the different static temperatures for the atoms, molecules and ions. The plasma potential is adjusted for neutrality at the end of the switch-on phase. During the 
post-discharge regime, it is dynamically determined to ensure a zero net current to the walls. The code calculates self-consistently the electron energy distribution function (EEDF) through the time-dependent Boltzmann equation [44] and the densities of $\mathrm{H}, \mathrm{H}_{2}, \mathrm{H}^{+}, \mathrm{H}_{2}^{+}, \mathrm{H}_{3}^{+}$, from kinetic equations including diffusion and recombination on the walls [45].

- a second model (model 2) which is similar to model 1 but also calculates the kinetics of vibrationally excited molecules; however, model 2 does not adjust the plasma potential for neutrality in the post discharge. This model was first developed by Gorse and coworkers [39]. The vibrational excitation of molecules $\mathrm{H}_{2}(v)$ by electronic collisions and their relaxation by atomic and wall collisions are included. In the present work, a new version of the code, faster and more accurate over long time scales, has been used [46]. Part of the cross-sections involved have been updated, including vibrational excitation by energetic electrons and $\mathrm{V}-\mathrm{T}$ relaxation by atomic collisions [47]. There are two adjustable parameters, namely the wall quenching of vibration which was adjusted to match the decay of $\mathrm{N}_{2}(v=1)$ at switch-off (at $0.53 \mathrm{~Pa}$ ) and the atomic recombination coefficient at the walls. The code computes the electron density and temperature; under stationary conditions, comparison with experiment is possible and good agreement is obtained for these two parameters.

3.2.1 Switch-on. - At switch-on, the disturbances caused to the gas by the previous discharge pulse applied $200 \mathrm{~ms}$ earlier have decayed and some "dischargeless" equilibrium prevails.

- Rotation. - At all pressures, the rotational temperature of $v=0$ rises in a few hundred $\mu$ s (Figs. 6, 7). It is quite interesting to monitor the change in density of each rotational state (Fig. 6). Before switch-on, a slight deficit in para $\mathrm{H}_{2}$ density is seen. At $50 \mu \mathrm{s}$ after switch-on, $J=0$ suffers a serious drop while $J=1$ drops slightly and the other states grow slightly. The substantial population displaced from $J=0$ is evidently already gone to higher para states, since the population gain in $J=2$ is quite small. At later times, the process accelerates and steady state is practically achieved at $200 \mu \mathrm{s}$. Complementary results at 5.3 and $0.53 \mathrm{~Pa}$ are shown in figures $7 \mathrm{a}$ and $\mathrm{b}$ for the temperature as measured from $J=1$ and 3 . The fast rise and decay are evident. The rotational temperature overshoots the steady-state value of $550 \mathrm{~K}$ by $100 \mathrm{~K}$ for a short period of time shortly after the center of the current pulse; it has returned to the $550 \mathrm{~K}$ value at approximately $1 \mathrm{~ms}$. The value of $T_{\text {rot }}$ also rises near the wall, also immediately at switch-on, but is less pronounced and does not present an overshoot. The main agents of excitation are the electrons. The atoms, which cause vibrational cooling, appear slowly according to the predictions of our models (see Fig. 8 for model 1) and have only modest influence at the beginning. The present results are also consistent with measurements in a similar source [48] which showed establishment of steady-state in under $200 \mu$ s for the kinetics of electron density and temperature.

- Density. - The rapid heating is accompanied by a compression effect, associated with the fact that the gas suddenly heated by the discharge does not have the time to expand through the openings provided in the reactor walls for optical access and passage of the filaments; in effect, the relaxation of a pressure imbalance between reactor and bell jar is estimated to take place in $10-20 \mathrm{~ms}$ at $300 \mathrm{~K}$, given the total area of these openings $\left(\approx 10 \mathrm{~cm}^{2}\right)$. In the $5.3 \mathrm{~Pa}$ case (Figs. 9a,b), the $\mathrm{H}_{2}$ partial pressure is seen to reach about $6 \mathrm{~Pa}$ near $0.5 \mathrm{~ms}$, then to begin to drop toward its steady-state value of $\approx 4 \mathrm{~Pa}$ as the dissociation and the atomic temperature and partial pressure are increasing. The discharge pulse is not long enough for steady state to be attained, but, as expected, the pressure history is identical at $r=0$ and $7.5 \mathrm{~cm}$ within experimental uncertainty. The $\mathrm{H}_{2}$ partial pressure increases only by $20 \%$ and does not reach its potential maximum of $\approx 10 \mathrm{~Pa}$, which one would expect from the doubling of the static temperature observed near the filaments. This is because the molecules dissociate, also because a sizeable fraction of the volume of the generator is not as strongly excited and heated as the 


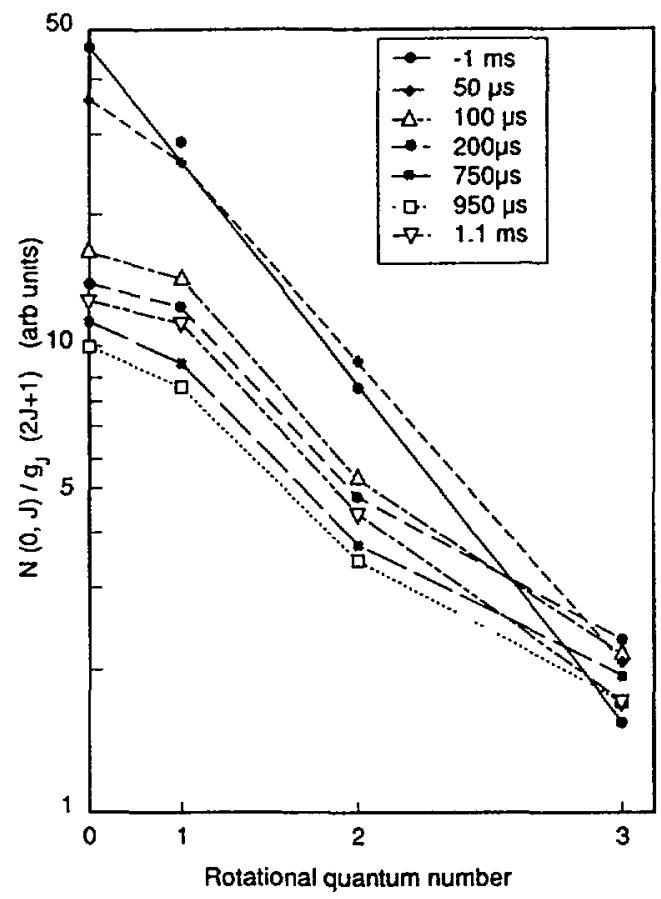

Fig. 6. - Boltzmann plots of rotational state densities in $v=0$ for different times and at $2.76 \mathrm{~Pa}$.
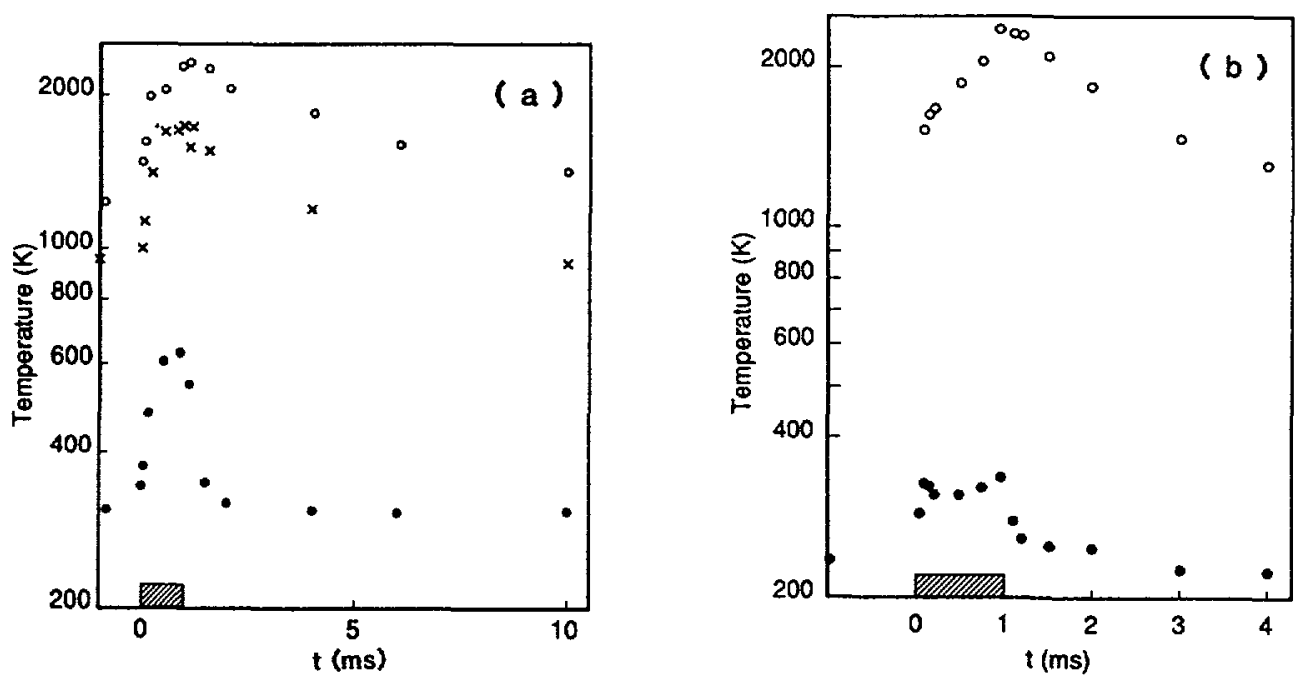

Fig. 7. - Rise and decay of temperatures of rotation $T_{\text {rot }}(v=0)(\bullet)$ and of vibration $T_{\text {vib }}(0)$ on the generator axis $(r=0)$ and for $5.3 \mathrm{~Pa}(\mathrm{a})$ and $0.53 \mathrm{~Pa}(\mathrm{~b})$, with 1 -ms-long discharge pulse (shown by hatched rectangle). $T_{\text {vib }}$ is also shown at $r=7.5 \mathrm{~cm}$ and $5.3 \mathrm{~Pa}(\times)$. 


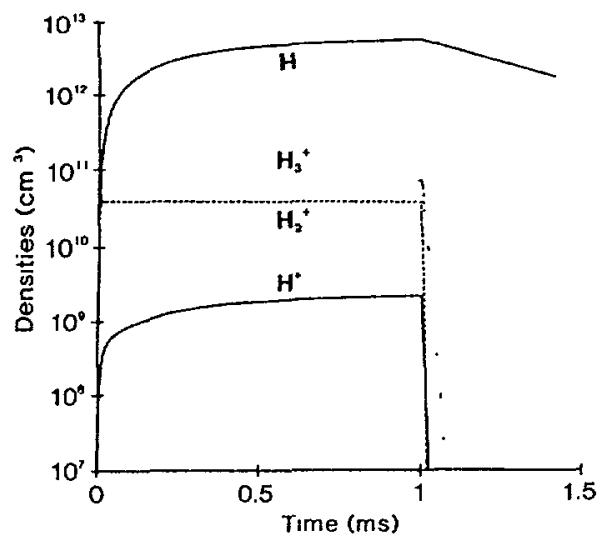

Fig. 8. - Numerical simulation by model 1 of electronic and $\mathrm{H}$ atom densities through the square, $1 \mathrm{~ms}, 10 \mathrm{~A}, 90 \mathrm{~V}$ discharge pulse.

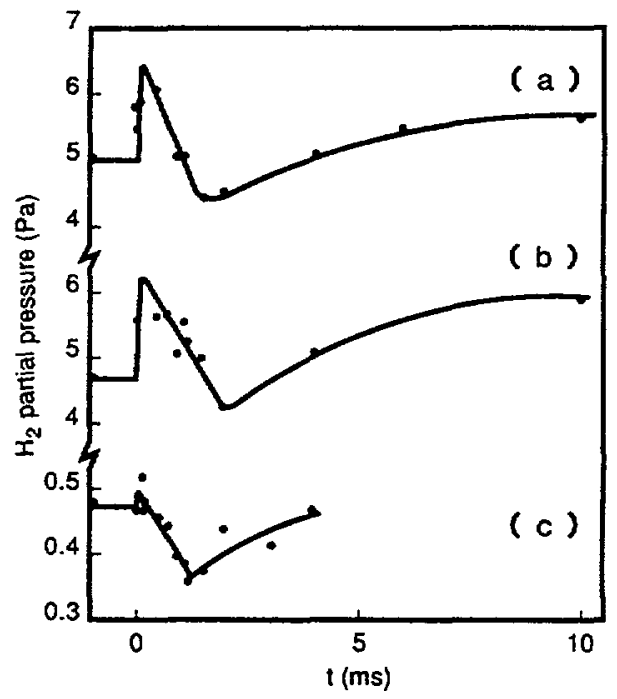

Fig. 9. - Plots of $\mathrm{H}_{2}$ pressure variations for the $5.3 \mathrm{~Pa}$ case at $r=0(\mathrm{a}), r=7 \mathrm{~cm}(\mathrm{~b})$, and for $0.53 \mathrm{~Pa}, r=0$ (c).

vicinity of the filaments and because a small fraction of the gas escapes through the openings in the reactor walls.

Also interesting is the fact that, before switch-on, the $\mathrm{H}_{2}$ pressure is slightly less than the nominal value by $5-10 \%$ at both $r=0$ and $r=7.5 \mathrm{~cm}$. This pressure deficit is comparable to or slightly larger than the experimental error, i.e. $5 \%$, and the result is systematic. Unless the $\mathrm{H}_{2}$ pressure measurement is biased as, e.g., if $T_{\mathrm{t}} \neq T_{\text {rot }}(v=0)$, the pressure defect indicates the presence of other species such as $\mathrm{H}$-atoms. The latter can be produced by dissociation of the molecules when they collide with the filament, as shown by the spatially-resolved measurements of Meier et al. [50]. 
- Vibration. - An important phenomenon, revealed by the Fig. 9, is that, at $5.3 \mathrm{~Pa}$ before switch-on, the vibrational temperature has a value of $1275 \mathrm{~K}$ which is well above $T_{\text {rot }}(v=0)$. Furthermore, this value is lower near the walls $(911 \mathrm{~K})$ than on the axis close to the filaments. (The latter property is more striking when one considers the density of $\mathrm{N}_{2}(v=1)$, which is typically six times lower at the wall than the center.) This rules out wall recombination of atomic hydrogen as the dominant source of vibrationally excited $\mathrm{H}_{2}$ in our generator during afterglow, since one would then expect $T_{\text {vib }}$ to be uniform. One explanation of the high vibrational temperature near the filaments is, again, that the filaments create between their two ends a confined, "mini-discharge" which collisionally populates vibrational states. We do not conclude, however, that formation of vibrationally excited $\mathrm{H}_{2}$ by recombinative desorption is absent here, or that it is negligible in other sources of similar nature $[4,5,15,37,49]$, yet the "mini-discharge" constitutes a satisfactory interpretation of the "dischargeless" results obtained by these groups, including the presence of vibrational states as high as $v=7$. As a matter of fact, as long as the filaments are heated under a voltage of $\gtrsim 1 \mathrm{~V}$, they can sufficiently accelerate the thermionic electrons which they emit to form vibrationally excited $\mathrm{H}_{2}$.

The rise of $T_{\mathrm{vib}}$ at $r=7.5 \mathrm{~cm}$ and for $5.3 \mathrm{~Pa}$ is less pronounced than at $r=0$ (Fig. 10), although the steady-state discharge values are the same at the two positions (Fig. 3). It is quite likely that this is because the majority of the $v=1$ molecules are produced away from the walls, closer to the filament and take some time to diffuse through the rest of the reactor. At $r=0$ for $0.53 \mathrm{~Pa}$ (Figs. $7 \mathrm{~b}, 9 \mathrm{c}$ ), little change is seen in either the time response or the numerical values compared with the $5.3 \mathrm{~Pa}$ case. Note that our detection sensitivity is insufficient to monitor $\mathrm{N}_{2}(v=1)$ just before switch-on. We assume $T_{\mathrm{v}} \lesssim 1000 \mathrm{~K}$ at that position.

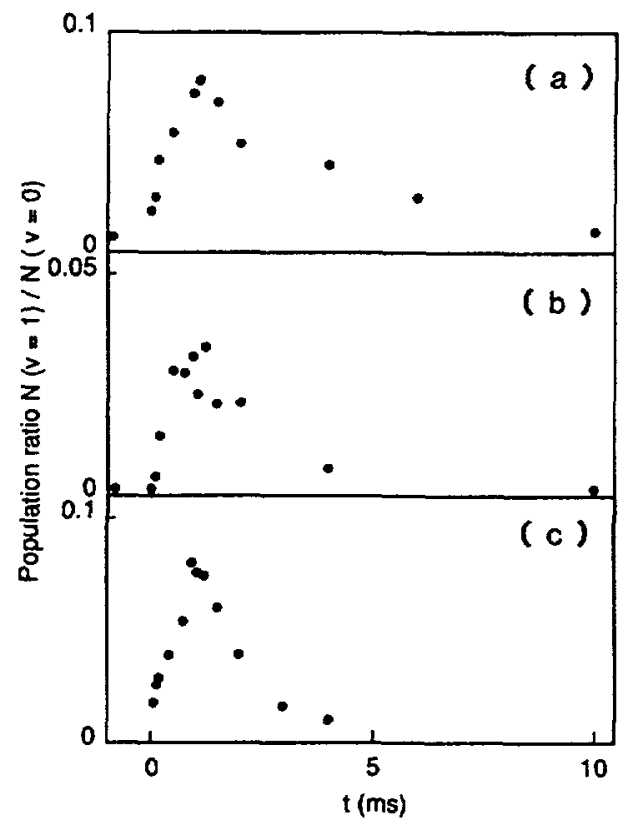

Fig. 10. - Plots of $v=1$ density normalized to $v=0$ at $r=0$ (a), $r=7 \mathrm{~cm} \mathrm{(b),} \mathrm{and} \mathrm{for} 0.53 \mathrm{~Pa}$, $r=0(c)$. 
3.2.2 Switch-off. - At switch-off, the electron temperature and density drop very rapidly, on time-scales of $50-200 \mu \mathrm{s}$ [48]. Important phenomena are visible from the figures.

- Rotation. - The decay of rotational excitation is very fast, and takes place in 100 $200 \mu$ s regardless of pressure (Fig. 7); this is comparable to those of ion density and electron temperature and density (see Fig. 8 and Hopkins and Graham [48]. This result is readily interpreted at $0.53 \mathrm{~Pa}$ (Fig. 7c) because this time scale is also comparable to the mean time between wall collisions. The result at $5.3 \mathrm{~Pa}$ is surprising, since the heat diffusion to the wall requires times of the order of $0.5-1 \mathrm{~ms}$. The fast drop in the population of $J=3$ which is actually seen could result from the superelastic collisions with low-energy electrons. The latter are far more mobile than the molecules and could evacuate the heat to the colder molecules close to the walls.

- Density. - The temperature drops very quickly to its pre-discharge level, which permits direct comparison of $p_{\mathrm{H}_{2}}$ values before and after the discharge and clearly reveals the deficit in $\mathrm{H}_{2}$ molecules resulting from dissociation and from leaks through the openings in the walls driven by the discharge overpressure (Fig. 9). The drop in $\mathrm{H}_{2}$ pressure with respect to the dischargeless steady state reaches $20 \%$ at $0.5-1 \mathrm{~ms}$ after switch-off at both 5.3 and $0.53 \mathrm{~Pa}$, indicating that some dissociation has been accomplished in $1 \mathrm{~ms}$. The ensuing pressure recoveries are very similar for the three cases presented. Also notable is the overshoot visible at $5-10 \mathrm{~ms}$ which stays at the same level until $20 \mathrm{~ms}$ (data points not shown in the figures), which is reproducible and slightly exceeds measurement uncertainties. This overshoot may be caused by wall recombination (recombinative desorption) of the excess free $\mathrm{H}$ atoms produced by the dischage and by the outgassing of $\mathrm{H}$ atoms implanted below the metal surface by ion bombardment.

- Vibration. - The vibrational population is characterised by slow decays. The relaxation times are typically in the range of $1.4 \mathrm{~ms}$ at $0.53 \mathrm{~Pa}$ (Fig. 10c) to $4 \mathrm{~ms}$ at $5.3 \mathrm{~Pa}$ (Fig. 10a) and $r=0$. Because diffusion complicates the study of molecular interaction with the wall, the results at $5.3 \mathrm{~Pa}$ are difficult to analyse. However, it is possible to extract some information from those at $0.53 \mathrm{~Pa}$. Because the molecules rarely collide with other molecules between two wall bounces, the decay in vibrational population is mainly caused by wall deactivation. A simulation of the result of figure $10 \mathrm{c}$ was performed with model 2, adjusting the probability $b(v)$ of wall deactivation of state $v$. The rate of decay of the population $N_{v}$ in state $v$ used in the model is given by [38]:

$$
\frac{\mathrm{d} N_{v}}{\mathrm{~d} t}=\frac{1}{4} \frac{\mathrm{S}}{\mathrm{V}} \overline{\mathrm{v}}\left\lceil\sum_{v^{\prime}>v} \frac{N_{v^{\prime}}}{v^{\prime} b\left(v^{\prime}\right)}-\frac{N_{v}}{b(v)}\right\rceil
$$

where $\bar{v}$ is the mean molecular velocity, $V$ the reactor volume and $S$ the area of its walls. Following Karo and Hiskes [51], a linear variation is assumed for $b^{-1}(v)$, with $b(14)=1$ and $b(1)$ adjusted to fit the present experimental result. To simulate the production of vibrationally excited molecules at $1000 \mathrm{~K}$ near the filament and in the absence of discharge, a dc discharge of $\sim 0.3 \mathrm{~A}$ is assumed to be maintained before and after the square pulse. A satisfactory agreement is obtained (Fig. 11) for $b(1)=1 / 16$. Allowing for the various experimental and geometrical uncertainties, we conclude that the probability of survival of state $v=1$ is $16 \pm 5$ collisions. The figure also shows the experimental and simulated behaviours of the vibrational population to be in fair agreement with each other during the discharge. 


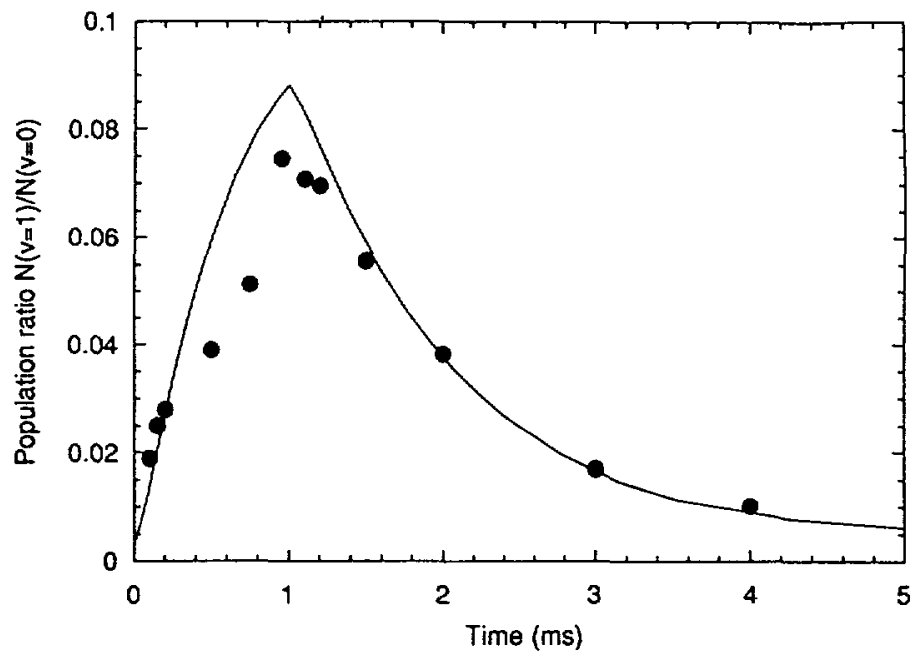

Fig. 11. - Numerical simulation by model 2 and for conditions of figure 10c, and experimental measurement of time dependence of $\mathrm{N}_{2}(v=1)$ taken from figure $10 \mathrm{c}$.

\section{Conclusion.}

Some progress has been made in the understanding of several aspects of the dynamical behaviour of neutral species in the magnetic multipolar $\mathrm{H}_{2}$ plasmas. We have seen that the ortho and para forms of $\mathrm{H}_{2}$ have slightly different temperatures, and that the para form is somewhat more sensitive to electronic collisions. Steady state measurements reveal this fact fairly clearly, but the transient experiments with the pulsed discharge confirm it without ambiguity by showing that the para $\mathrm{H}_{2}$ heats up faster than the ortho at switch-on.

Interesting facts are also learned about the vibration. The population of state $v=1$ falls off in $1.4 \mathrm{~ms}$ after switch-off, indicating that $16 \pm 5$ wall collisions may be needed for the vibrational deactivation. It was also noted in the dischargeless case that the vibrational temperature is larger in the vicinity of the filament than near the walls at $5.3 \mathrm{~Pa}$, ruling out recombinative desorption of $\mathrm{H}$ atoms as the main mechanism of production of vibrationally excited molecules by an unbiased Joule-heated filament.

The results also stress the usefulness of CARS in such plasmas. CARS is still the only spatially resolved in situ technique for sensing the molecules. While it does not appear to be as sensitive as the other methods of VUV absorption and REMPI, it competes favorably with VUV absorption if the latter is imposed the same optical path as the spatial resolution in CARS, and REMPI cannot operate in situ in discharges. Finally, CARS retains a significant potential for progress in detection sensitivity. With the use of better spectrographs and by implementing multiple pass amplification [14], gains of 2-10 in detectivity could be achieved. The spectral resolution can also be improved, giving access to the velocity distribution function; a resolution of $0.02 \mathrm{~cm}^{-1}$ would be amply sufficient.

\section{Acknowledgements.}

The authors are extremely grateful to P. Bréchignac, C.B. Moore, P. Toennies, J.R. Wadehra 
and J. Wolfrum for enlightening discussions and for supplying many documents and literature references. Partial support from Direction des Recherches, Etudes et Techniques is gratefully acknowledged. Computational resources were granted by the Conseil Scientifique du Centre de Calcul Vectoriel pour la Recherche, France.

\section{References}

[1] KUNKeL W.B., IEEE Trans. Nucl. Sci. 26 (1979) 4166.

[2] Bacal M., Bruneteau A.M. and Nachman M., J. Appl. Phys. 55 (1984) 15.

[3] Leung K.N., Ehlers K.W. and PyLe R.V., Rev. Sci. Instrum. 56 (1985) 364.

[4] BonNiE J.H.M., Multiphoton Ionization for Hydrogen Plasma Diagnostics, thesis, University of Amsterdam (Nov, 1987).

[5] Bonnie J.H.M., Eenshuistra P.J. and Hopman H.J., Phys. Rev. A37 (1988) 1121.

[6] Stutzin G.C., Young A.T., Schlachter A.S., Stearns J.W., Leung K.N., Kunkel W.B., WORTH G.T. and STEVENS R.R., Rev. Sci. Instrum. 59 (1988) 1363.

[7] Robie D.C., Jusinski L.E. and Bischel W.K., VI Gaseous Electronics Conference, Paper H-39, Minneapolis, Minnesota (1988).

[8] Eenshuistra P.J., KLeiJn A.W. and Hopman J.H., Europhys. Lett. 8 (1989) 423.

[9] BACAL M., Nucl. Instrum. \& Methods Phys. Res. B37/38 (1989) 28.

[10] Hiskes J.R. and Karo A.M., Appl. Phys. Lett. 54 (1989) 508.

[11] Marinero E.E., RetTiner C.T. and Zare R.N., Chem. Phys. Lett. 95 (1983) 486.

[12] Druet S.A.J. and Taran J.-P.E., Prog. Quant. Electr. 7 (1981) 1.

[13] Pélat M., Taran J.-P.E., Taillet J., Bacal M. and Bruneteau A.M., J. Appl. Phys. 52 (1981) 2687.

[14] Péalat M., Taran J.-P.E., Bacal M. and Hillion F., J. Chem. Phys. 82 (1985) 4943.

[15] Bonne J.H.M., Granneman E.H.A. and Hopman H.J., Rev. Sci. Instrum., 58 (1987) 1353.

[16] Bruneteau A.M., Hollos G., Bacal M. and Bretagne J., IAEA Technical Committee Meeting on Negative Ion Beam Heating, 15-17 July 1987, Culham Laboratory, G.B.

[17] Bruneteau A.M., Hollos G., Bacal M. and Bretagne J., J. Appl. Phys. 67 (1990) 7254.

[18] Buchenau H., Herrero V.J., Toennies J.P. and Vodegel M., VII European Molecular Conference on Dynamics of Molecular collisions, Assisi (Perugia), Italy (5-9 September 1988).

[19] VALENTINI J.J. and PhILLIPS D.L., "Experimental and Theoretical Studies of the Dynamics of the Hydrogen Exchange Reaction: The Maturation of a Prototype" in "Gas Phase Bimolecular Reactions" M.N.R. Ashfold and J.E. Baggot, Eds. (Royal Society of Chemistry, London, 1989).

[20] Boquillon J.P., Péalat M., Bouchardy P., Collin G., Magre P. and Taran J.-P.E., Opt. Lett. 13 (1988) 722.

[21] Phelps A.V., J. Phys. Chem. Ref. Data 19 (1990) 653.

[22] ECKBreth A.C., Appl. Phys. Lett. 32 (1979) 421.

[23] Débarre D., Lefebvre M., Péalat M., Taran J.-P.E., Bamford D.J. and Moore C.B., J. Chem. Phys. 83 (1985) 4476.

[24] Massabieaux B., Gousset G., Lefebvre M. and M. Péalat, J. Phys. France 48 (1987) 1939.

[25] MASSEY H.S.W., BURHOP E.H.S. and GILBODY H.B., Electronic and Ionic Impact Phenomena, Second Edition, 3 (Clarendon, Oxford, 1971).

[26] Lane N.F., Rev. Mod. Phys., 52 (1980) 29.

[27] Henry R.J.W. and Chang E.S., Phys. Rev. A5 (1972) 276.

[28] Treanor C.F., Rich J.W. and Rehm R.G., J. Chem. Phys. 48 (1968) 1789.

[29] Basov N.G., Mikhailov V.G., OraevskiI A.N. and Scheglov V.A., Sov. Phys. Techn. Phys. 13 (1969) 1630. 
[30] Valley L.M. and Amme R.C., J. Acoust. Soc. Am. 44 (1968) 1144.

[31] Wolfrum J., Faraday Discuss. Chem. Soc. 84 (1987) 191.

[32] F arrow R.L. and Chandler D.W., J. Chem. Phys. 89 (1988) 1994.

[33] Lefebvre M., PÉalat M., Taran J.-P. and BaCal M. Study of a hydrogen plasma by CARS ONERA technical Rep. 62/7131 PN (october 1991).

[34] Thomas L.B., in "Rarefied Gas Dynamics", Progress in Astronautics and Aeronautics, M. Summerfield Series Ed. 74 (AIAA, New York, 1981) p. 83;

TAMM P.W. and SCHMIDT L.D., J. Chem. Phys. 51 (1969) 5352;

RetTner C.T., Delouise L.A., Cowin J.P. and Auerbach D.J., Faraday Discuss. Chem. Soc. 80 (1985) 127.

[35] Herlin N., Lefebvre M., Péalat M. and Parlier M., presented at EURO-CVD 7, Perpignan, France 19-23 June 1989, J. Phys. Colloq. France 50 (1989) C5-843;

Herlin N., Péalat M., Lefebvre M. and Alnot P., Surface Sc. 258 (1991) 381.

[36] Young A.T., Stutzin G.C., Kunkel W.B. and LeUng K.N., AIP Conference Proc. 210 (1990) 450.

[37] Hall R.I., Cadez I., Landau M., Pichou F. and Scherman C., Phys. Rev. Lett. 60 (1988) 337.

[38] Gorse C., Capitelil M., Bacal M., Bretagne J. and Lagana A., Chem. Phys. 117 (1987) 177.

[39] Gorse C., Capitelli M., Bretagne J. and Bacal M., Chem. Phys. 93 (1985) 1.

[40] WadeHRA J., in "Nonequilibrium Vibrational Kinetics", Topics in Current Physics, 39 M. Capitelli Ed. (Springer-Verlag, Berlin, New-York, 1986).

[41] Bacal M., Berlemont P. and Skinner D.A., Volume Production of Hydrogen Negative Ions, OE/LASE'89 SPIE Meeting (Los Angeles, USA, 15-20 Jan. 1989).

[42] Eenshuistra P.J., Heeren R.M.A., Kleyn A.W. and Hopman H.J., Phys. Rev. A40 (1989) 3613.

[43] Ortobaev D.K., Ochkin V.N., Preobrazhenski N.G., Savinov S.Yu., Sedelnikov A.I. and Sobolev N.N., Sov. Phys. JETP 54 (1981) 865.

[44] Bretagne J., Delouya G., Gorse C., Capitelli M. and Bacal M., J. Phys. D18 (1985) 811; D19 (1986) 1197.

[45] Jacquin D., Bretagne J. and Ferdinand R., Plasma Chem. Plasma Proc. 9 (1989) 165.

[46] Skinner D.A., Berlemont P. and Bacal M., Proc. $4^{\text {th }}$ European Workshop on the Production and Application of Light negative Ions, Belfast, W.G. Graham Ed., Queen's University of Belfast, 26-28 March 1991, p. 1.

[47] Capitelli M., Gorse C., Berlemont P., Skinner D.A. and Bacal M., Chem. Phys. Lett. 179 (1991) 48.

[48] Hopkins M.B. and Graham W.G., J. Appl. Phys. 69 (1991) 3461.

[49] Eenhuistra P.J., Bonnie J.H.M., Los J. and Hopman H.J., Phys. Rev. Lett. 60 (1988) 341.

[50] Meier U., KohSE-HöINGHaus K., SChäFer L. and Klages C.-P., Appl. Opt. 29 (1990) 4993.

[51] KaRo A.M., Hiskes J.R. and HaRdY R.J., J. Vac. Sci. Technol. A3 (1985) 1222. 